\title{
Avaliação de um programa informatizado para promoção do repertório de ler com compreensão
}

\author{
Marcelle Teixeira Bertini \\ Camila Muchon de Melo
}

\section{RESUMO}

A leitura está presente em várias situações do cotidiano, como na aquisição de conteúdos acadêmicos e em situações práticas do dia-a-dia, portanto, quem a compreende apresenta maior autonomia para interagir com o ambiente. $\mathrm{O}$ objetivo deste estudo foi avaliar a eficiência do Módulo 3, parte do Currículo de Ensino "Aprendendo a ler e a escrever em pequenos passos", na promoção da leitura com compreensão e da fluência de leitura. 0 Módulo 3 era composto por 15 livros com a finalidade de promover comportamentos de identificar fatos explícitos nos textos, fazer inferências, identificar o tema da história e aprender vocabulário contextual. Participaram do estudo 11 crianças do ensino fundamental, separadas em grupo controle e experimental. Foram utilizadas medidas de compreensão textual e de fluência de leitura antes e após o procedimento de ensino, as quais foram analisadas com o programa estatístico $\mathrm{R}$ Core Team. Foi demonstrado aumento significativo na medida de compreensão de textos para as crianças do grupo experimental, quando comparados os resultados com o grupo controle. Sobre a fluência de leitura, não houve diferença significativa entre as medidas na comparação entre os grupos, entretanto o grupo experimental apresentou aumento significativo da medida quando comparado com ele mesmo.

Palavras-chave: programa de ensino; leitura com compreensão; fluência de leitura; Análise do Comportamento; crianças.

\section{ABSTRACT \\ Evaluation of a computerized program for the development of a reading comprehension repertoire}

Reading is present in many situations of our everyday life such as in the acquisition of academic contents and in our daily practical situations; however, those who understand it shows more autonomy to interact with the environment. The objective of this study was to evaluate the efficiency of Module 3, part of the Teaching Curriculum "Learning to read and write in small steps", towards the improvement of the reading comprehension and reading fluency. Module 3 includes 15 books with the objective to promote the identification of explicit facts in the texts, to make inferences, to identify the theme of the story and to learn contextual vocabulary. Eleven elementary school children participated in the study divided into a control group and an experimental group. The study adopted text comprehension reading fluency measures before and after the teaching procedure, analyzed by the R Core Team statistical program. Results showed significant increase in the text comprehension measure for children from the experimental group when compared to the results from the control group. In regards to reading fluency, there was no significant difference between the comparative measures between the groups; however, the experimental group showed significant increase in this measure, when compared to itself.

Keywords: teaching program; reading with comprehension; reading fluency; Behavior analysis; children.

\section{Sobre os autores}

M. T. B.

http://orcid.org/0000-00030441-3630

Universidade Estadual de Londrina- Londrina, PR

marcelletb@hotmail.com

\section{M. M.}

http://orcid.org/0000-00016484-5297

Universidade Estadual de Londrina- Londrina, PR

camuchon@uel.br

\section{Direitos Autorais}

Este é um artigo de acesso aberto e pode ser reproduzido livremente, distribuído, transmitido ou modificado, por qualquer pessoa desde que usado sem fins comerciais. 0 trabalho é disponibilizado sob a licença Creative Commons CC-BY-NC.

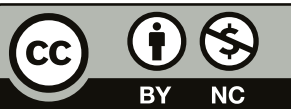




\section{H* INTERACÃO EM 4T. PSICOLOGIA}

O ensino da leitura com compreensão é fundamental para os indivíduos desenvolverem autonomia para interagir com o ambiente. A leitura está presente em situações simples, como decifrar uma placa ou em situações mais complexas, como na aquisição de repertórios acadêmicos. Dados do Indicador de Alfabetismo Funcional - INAF (2018) demonstram que apenas $49 \%$ dos entrevistados chegaram ao Ensino Médio funcionalmente alfabetizados, situação preocupante para a população brasileira e que demanda reformulação do sistema de ensino para esse aprendizado. De acordo com Skinner (1957), a leitura com compreensão pode ser analisada como um comportamento operante verbal. Ao ler, o leitor emite respostas verbais sob controle de estímulos impressos, visuais ou táteis, como no caso do braile, e se comporta como falante e ouvinte do seu próprio comportamento verbal (de Souza et al., 2014). Neste caso, é preciso que o leitor compreenda as palavras emitidas por ele mesmo, como se elas fossem faladas por outra pessoa.

Para entender a classe de comportamentos de leitura com compreensão, o conceito de comportamento operante verbal textual de Skinner é fundamental. Segundo o autor (1957), no comportamento textual, o leitor visualiza ou tateia símbolos ordenados que correspondem às palavras faladas e emite sons. Esta relação entre estímulos impressos e respostas verbais é estabelecida por conta das contingências de reforço dispostas por uma comunidade verbal: agentes educacionais utilizam reforços condicionados a respostas vocais que correspondem a determinados grafemas, por exemplo. Apesar dessas características, Skinner (1957) afirma que o conceito de comportamento textual descreve somente a emissão das respostas verbais sob controle do texto, desta maneira, o indivíduo pode ler a palavra, mas não compreender o seu significado. Essa relação pode ser exemplificada na aprendizagem de uma língua estrangeira: é possível emitir a resposta vocal sob controle do estímulo discriminativo/texto corretamente, sem que haja, necessariamente, a compreensão da palavra lida (de Souza, de Rose, \& Domeniconi, 2009).

Portanto, para ler com compreensão, além de estabelecer relações entre palavras faladas e seus correspondentes gráficos (palavras escritas), é fundamental que o leitor saiba relacionar as mesmas palavras aos seus correspondentes no mundo. Sidman (1994) afirma que a leitura com compressão ocorre quando há formação de uma classe de equivalência entre os estímulos (a) palavras faladas, (b) palavras impressas e (c) objetos do ambiente. A partir da formação da classe de equivalência, o sujeito passa a se comportar de maneira semelhante frente a cada um desses estímulos, devido às suas propriedades intercambiáveis de simetria, transitividade e reflexividade.

Segundo de Rose (1993), dizer que uma palavra tem significado implica dizer que esta palavra é um estímulo equivalente
Marcelle Teixeira Bertini e Camila Muchon de Melo

a outro conjunto de estímulos como objetos, sensações, qualidades etc. Desta maneira, a classe de estímulos que se tornou equivalente à palavra é o seu significado. 0 autor também ressalta a importância do controle contextual na formação das classes de equivalência, na qual o significado de uma palavra só é válido em um contexto específico. Rocca (2012) exemplifica essa relação ao mostrar palavras que têm a mesma topografia, mas que nem sempre têm o mesmo significado. Como no caso da palavra "manga", a qual pode se referir a uma fruta ou à parte de uma camisa. Desta maneira, tem-se que o significado de uma palavra é estabelecido também no contexto em que ela é emitida e não somente por sua topografia.

Autores como Layng, Sota, e Leon (2011) também afırmam que ler com compreensão envolve um controle de estímulos restrito: o leitor deve ter o seu repertório verbal guiado por relações de controle de estímulos semelhantes às utilizadas pelo autor do texto, as quais foram estabelecidas por meio de sua história de vida. Além disso, o leitor deve desenvolver dois repertórios comportamentais integrados, denominados de "repertório verbal" e "repertório investigativo". O repertório verbal está relacionado à quantidade de palavras conhecidas pelo leitor ao longo de sua história de interação comportamental com o ambiente (vocabulário). Já o repertório investigativo define que o leitor deve agir adequadamente de acordo com o tipo de questão de interpretação a respeito de um texto. Os autores exemplificam esse aspecto dizendo que há diferentes questões sobre compreensão, as quais podem ser de múltipla escolha, exigirem respostas escritas, pedirem respostas literais, inferenciais etc. e que demandam comportamentos diferentes do leitor. Portanto, esse deve saber se comportar de acordo com o estímulo textual/pergunta para demonstrar que compreendeu o texto.

Outro aspecto relevante para ler com compreensão é a fluência de leitura. A fluência se caracteriza como a habilidade de ler com acurácia e rapidez as palavras contidas em um texto, processo geralmente desenvolvido nos primeiros anos de alfabetização e que está relacionado com a correspondência entre a letra e o seu som (Cardoso-Martins \& Navas, 2016). Embora não haja consenso teórico para essa definição, estudos apontam a fluência de leitura como o resultado da qualidade da leitura oral de palavras isoladas e de textos, a qual pode ser medida por meio da (a) taxa de leitura (velocidade, número de palavras lidas por minuto - automaticidade no processamento da associação fonema-grafema), (b) precisão (palavras lidas corretamente) e (c) prosódia (ler corretamente a pontuação, utilizando a entonação) (Ehri, 2005; Horne, 2017; Navas, Pinto, \& Dellisa, 2009).

Tendo em vista a importância e a abrangência da leitura com compreensão é possível que ela seja desenvolvida ou maximizada a partir de arranjos de contingências ambientais, podendo suprir dificuldades de aquisição desse repertório. A 


\section{M." INTERACÃO EM 4T PSICOLOGIA}

Tecnologia do Ensino, proposta por Skinner (1968/1972), possibilita o ensino de comportamentos relevantes para aquisição de um repertório específico ou para suprir um repertório incipiente, priorizando as características comportamentais de cada indivíduo. Baseado em princípios de aprendizagem, a Tecnologia de Ensino (Holland \& Skinner, 1961; Keller, 1968; Skinner, 1968/1972) prevê a participação ativa do aprendiz como parte do processo de aprendizagem, por meio de: a) um arranjo de contingências que permitam que o aprendiz responda e tenha consequenciação imediata para sua resposta; b) o progresso do aprendiz no seu próprio ritmo, portanto, deverá resolver corretamente um número necessário de questões para avançar para uma fase mais complexa; c) o desenvolvimento do material em pequenos passos para desenvolver comportamentos necessários para aquisição do repertório que se pretende ensinar; d) um programa reforçador para o comportamento do aprendiz de executar a tarefa, arranjado de forma que diminua a quantidade de erros apresentada pelo indivíduo (Skinner, 1968/1972). Após participar de um processo de ensino, o aprendiz deverá estar preparado para lidar com as demandas do seu ambiente, de acordo com o repertório comportamental que lhe foi ensinado.

Alguns procedimentos baseados na Análise do Comportamento e na proposta da Tecnologia de Ensino têm sido utilizados para desenvolver leitura com compreensão, como o currículo de ensino "Aprendendo a ler e a escrever em pequenos passos - ALLEP" (de Rose et al., 1989; de Rose, de Souza, \& Hanna, 1996; de Souza et al., 2004). O currículo contém três módulos, atualmente informatizados, que visam desenvolver repertórios de leitura e escrita mais básicos, utilizando palavras isoladas regulares e irregulares (Módulo 1 e 2), e repertórios mais complexos como leitura com compreensão de textos (Módulo 3). Este currículo foi desenvolvido para auxiliar crianças, jovens e adultos que não aprenderam a ler e a escrever, ou que apresentam dificuldades para aquisição desses repertórios. 0 currículo de ensino mostrou resultados positivos no ensino de leitura e escrita, principalmente na aplicação dos Módulos 1 e 2 (de Souza \& de Rose, 2006) com alunos do ensino fundamental (de Rose, et al., 1996; de Souza et al., 2009; de Souza et al., 1999; Hanna et al., 2004; Reis, de Souza, \& de Rose, 2009). Em estudo realizado por Reis et. al. (2009) foi demonstrado que a aplicação do Módulo 1 quando feita por professores com 64 alunos, para desenvolver leitura de palavras isoladas, apresentou média de $90 \%$ de acertos após o procedimento de ensino. Com indivíduos com desenvolvimento atípico, Benitez e Domeniconi (2012) demonstraram que a aplicação do Módulo 1 por familiares de indivíduos com deficiência intelectual aumentou a quantidade de palavras lidas se comparadas às medidas de pré-teste e pós-teste, embora este módulo não tenha sido desenvolvido especificamente para essa população. Carvalho (2013) utilizou o Módulo 2 do ALEPP adaptado para atender as necessidades de um participante com Transtorno
Marcelle Teixeira Bertini e Camila Muchon de Melo

de Asperger, e também encontrou resultados satisfatórios no desenvolvimento da leitura de palavras complexas, da leitura de palavras com encontros vocálicos e da leitura e escrita de palavras com fonemas semelhantes.

O "Módulo de Ensino 3 - Compreensão de Leitura de Textos" está em fase de desenvolvimento e testagem e foi elaborado para alunos a partir do quarto ano do Ensino Fundamental. Ele visa o ensino de compreensão de textos e o desenvolvimento de repertórios verbais com este nível de complexidade. Ele contém 15 livros divididos em três níveis de ensino que aumentam gradualmente de dificuldade. Sobre as histórias dos livros são apresentadas questões de compreensão textual com o objetivo de ensinar quatro classes de comportamentos: a) identificar fatos explícitos nos textos lidos, b) fazer inferências, c) identificar o tema da história e d) aprender vocabulário contextual. Ao "identificar fatos explícitos nos textos", o participante deve identificar estímulos textuais que estejam explicitamente presentes no texto. No caso da classe de comportamentos de "realizar inferências" não há uma correspondência textual entre as alternativas da questão e o texto lido, sendo necessário que o aluno formule uma resposta a partir de informações lidas anteriormente. Na terceira classe de comportamentos "identificar o tema da história", a criança deverá saber identificar o tema principal da história a partir das informações contidas nela. Na última classe de comportamento, "aprender vocabulário contextual", o aluno deverá aprender a relacionar frases ditadas ou impressas com figuras ou frases impressas correspondentes (Domeniconi et al., submetido).

É importante ressaltar que não foram encontrados muitos estudos que mostram a eficácia da aplicação deste módulo. Hanna et al. (2015b) demonstraram que o Módulo 3 foi eficaz para ensinar leitura com compreensão a crianças do Distrito federal, ao testarem o procedimento com 42 alunos do quarto ano. Aran (2016) demonstrou que o Módulo 3 auxiliou 20 crianças do Ensino Fundamental a melhorarem o repertório de leitura com compreensão, ao comparar medidas de pré-teste e pós-teste. Não foram verificados estudos que avaliaram o efeito do programa de ensino, "Aprendendo a ler e a escrever em pequenos passos", especificamente do Módulo 3, sobre a fluência de leitura, componente considerado necessário para realizar leitura com compreensão.

Desta maneira, o objetivo desta pesquisa foi avaliar a eficácia do Módulo 3, do ALLEP para promover comportamentos de leitura com compreensão e fluência de leitura em crianças do ensino fundamental, que apresentavam dificuldades para adquirir esses repertórios em condições de ensino convencional. A avaliação da eficácia do módulo na promoção da fluência de leitura foi inserida exclusivamente nesta pesquisa, visto que a aplicação original do Módulo 3 não previa e não utilizava medidas de fluência de leitura. 


\section{MÉTODO}

\section{LOCAL}

A pesquisa foi realizada em uma ONG localizada em um bairro de periferia em uma cidade do interior do Paraná. As sessões foram feitas em uma sala contendo oito computadores. As crianças ficaram posicionadas com aproximadamente $80 \mathrm{~cm}$ de distância uma da outra.

\section{MATERIAIS, INSTRUMENTOS E EQUIPAMENTOS}

Os equipamentos utilizados para a realização da coleta de dados foram três computadores, fones de ouvido, gravador de voz, lápis e papel sulfite.

\section{INSTRUMENTOS}

Subteste de leitura do Teste de Desempenho Escolar (TDE). Este subteste tem como objetivo verificar o reconhecimento e a leitura de palavras isoladas pelos examinandos. Ele contém 75 palavras escritas, em ordem crescente de dificuldade, apresentadas em uma folha estímulo. A quantidade de palavras lidas corretamente é classificada em superior, média ou inferior para cada série escolar, sendo que, o número de acertos igual ou menor a 65 palavras, sugere classificação inferior para alunos a partir do terceiro ano do ensino fundamental. É importante destacar que esse subteste foi utilizado para selecionar os participantes da pesquisa, portanto, alunos que leram 65 palavras corretas ou mais prosseguiram com 0 procedimento.

Durante a aplicação, o examinador solicita aos examinandos a leitura das palavras isoladas em voz alta e registra os erros e acertos. Caso o examinando erre na primeira tentativa em que lê a palavra, pede-se que leia novamente. A resposta é considerada correta se for lida sem erros na segunda tentativa (Stein, 1994).

DLE-3_Versão 1 e DLE-3_Versão 2. O "Diagnóstico da Rede de Leitura e Escrita 3_ Versão 1" ou (DLE-3_Versão 1) (Domeniconi, Silveira, \& Hanna, 2013) é um instrumento de avaliação, utilizado como medida de seleção de participantes e de pré-teste, e contém 24 questões (20 objetivas e quatro dissertativas), divididas entre seis diferentes textos (poesia, narrativa, tirinhas) para avaliar leitura com compreensão. 0 DLE-3_Versão 2 (Domeniconi, et al., 2013), utilizado como medida de pós-teste, é um instrumento de avaliação com estrutura semelhante ao DLE-3_Versão 1 (contém o mesmo número de questões e textos apresentados), porém apresenta textos com conteúdos diferentes da avaliação de pré-teste.

Como exemplo, no texto "Pontinho de Vista" do DLE-3_ Versão 1 é possível observar um trecho de texto e de duas perguntas utilizadas nesses instrumentos de avaliação: PONTINHO DE VISTA (Autor: Pedro Bandeira): "Eu sou pequeno, me dizem, e eu fico muito zangado. Tenho de olhar todo mundo com o queixo levantado. Mas, se formiga falasse e me visse lá do chão, ia dizer, com certeza: - Minha nossa, que grandão!".

Perguntas:

1) Marque a correta: Quem diria: "- Minha nossa, que grandão!"

a) A formiga, porque ele está com o queixo levantado;

b) A formiga, porque é menor que o menino;

c) 0 menino, que agora se olha no espelho;

d) A mãe do menino, que sabe que ele cresceu ou

e) $\mathrm{O}$ autor do texto por achar o menino alto.

2) Neste texto também é apresentada uma questão discursiva: Como o personagem do texto se sente em relação ao seu tamanho?

Textos para analisar a fluência de leitura (taxa de palavras lidas por minuto). Os textos utilizados para avaliar a fluência de leitura pertencem ao livro Compreensão de Leitura 1, de Alliende et al. (1994). Os textos escolhidos foram "O peixão e o peixinho" (124 palavras), para o pré-teste e "Um cacho de uvas" (146 palavras), para o pós-teste.

Programa de Ensino (ALLEP). 0 "Módulo de Ensino 3 Compreensão de Leitura de Textos" foi utilizado nesta pesquisa em uma versão informatizada, realizada por meio do programa Power Point (Domeniconi, et. al., submetido). 0 módulo é composto por 15 livros infantis divididos em três níveis de ensino. Cada nível contém cinco livros. Os livros utilizados fazem parte da coleção "Estrelinha", da autora Sônia Junquei$\mathrm{ra}$, os quais foram minimamente alterados para garantir um aumento gradual de dificuldade.

Os 15 livros foram organizados do mais simples para o mais complexo, obedecendo a seguinte ordem: 1-"Regina e o Mágico", 2- "O caracol viajante", 3- "O peru de peruca", 4-"A foca famosa", 5-"O menino e o muro" (primeiro nível de ensino); 6-"A onça e a anta", 7-"O macaco medroso", 8-"A arara cantora", 9-"O sonho da vaca", 10-"O barulho fantasma" (segundo nível de ensino); 11-"O peixe pixote", 12-“Um palhaço diferente", 13-"A festa encrencada", 14-"O susto do periquito", 15-“O mistério da lua" (terceiro nível de ensino). É importante ressaltar que foi alterada a ordem original de aplicação dos livros 8 (O sonho da vaca) e 9 (A arara cantora) de forma que o livro 9 foi aplicado antes do livro 8, da mesma maneira que houve antecipação do livro 14 (0 susto do periquito) no lugar do livro 13 (A festa encrencada). Essa alteração foi realizada de acordo com o estudo de Hanna et al. (2015a) o qual indicou maior número de erros apresentados pelos participantes no livro 8 se comparado com o 9 e no livro 13 se comparado com o 14. 


\section{4.' INTERACÃO EM ET PSICOLOGIA}

Com o objetivo de desenvolver os comportamentos de (a) identificar fatos explícitos, (b) realizar inferências, (c) identificar o tema da história e (d) aprender vocabulário contextual, os livros infantis são apresentados de forma gradual e cumulativa no ALLEP. É apresentada uma página por vez, intercalada por uma ou duas questões de compreensão de texto formuladas para desenvolver os comportamentos-objetivo, de acordo com as informações lidas. Em caso de dúvidas ou após uma resposta incorreta, o programa permite retomar a página anterior ou a toda informação lida até o momento (clicar a seta azul). É também permitido que o participante peça para o programa ler palavras sublinhadas no texto, quantas vezes for necessário (ver Figura 1). No formato original do programa, o participante deveria acertar todas as questões para avançar para um próximo livro, neste estudo, foi utilizado o critério de $90 \%$ de acertos.

As questões de compreensão são compostas por frases ditadas (A) ou impressas (C) (estímulos visuais ou auditivos) e as respostas compostas por frases impressas (C) ou figuras (B) (estímulos visuais). Deste modo, são apresentadas questões arranjadas entre frases impressas e frases impressas (CC), frases impressas e figuras (CB), frases ditadas e frases impressas (AC), frases ditadas e figuras (AC). Ao final da leitura e exercícios de cada livro, é apresentada uma última questão impressa e falada, na qual o participante escreve a resposta em uma folha sulfite separada. 0 objetivo dessa questão é sondar a escrita e verificar se ocorre novas verbalizações sobre o en- tendimento dos conteúdos abordados do texto, porém esses dados não foram analisados no presente estudo.

Consequências diferenciais imediatas eram apresentadas após acertos e erros dos participantes. Para os acertos eram exibidas animações variadas como "smiles", animais e pessoas dançando. Enquanto que para os erros era apresentada somente uma animação que indicava desaprovação e era previsto um procedimento de correção no qual a questão era reapresentada até que o participante a acertasse. Na sequência, o aprendiz prosseguia para a próxima página do livro e questão.

Na Figura 1 é mostrado um exemplo do procedimento utilizado no Módulo 3. Na primeira tela o participante pode ler o trecho do livro, após a leitura o participante passa para uma segunda tela em que a questão é apresentada: nesse exemplo arranjada entre frase impressa e frase impressa (CC). Em caso de resposta correta uma terceira tela aparece com uma consequência diferencial ("carinha feliz", para a resposta correta) ou, em caso de resposta incorreta, a terceira tela apresenta uma "carinha de desaprovação".

\section{PROCEDIMENTOS}

A partir da aprovação do Comitê de Ética em Pesquisa com Seres Humanos [Comitê de Ética em Pesquisa com Seres Humanos da Universidade Estadual de Londrina, CAAE $\mathrm{n}$. 53499215.7.0000.5231], os participantes foram selecionados por meio da aplicação do subteste de leitura do TDE e da
Tela 1

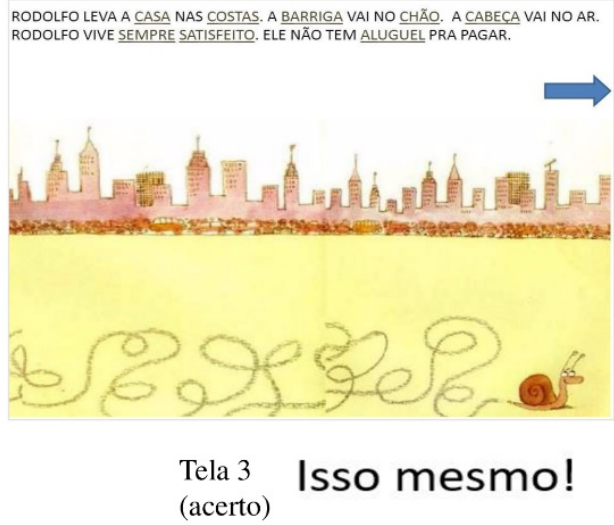

Tela 2

\section{O que Rodolfo leva nas costas...}

\begin{tabular}{|l|l|}
\hline (a) Um caminhão \\
\hline (b) Uma caixa \\
\hline (c) Uma bolsa \\
\hline (d) Uma casa \\
\hline
\end{tabular}

Tela 3 Tente outra resposta (erro)
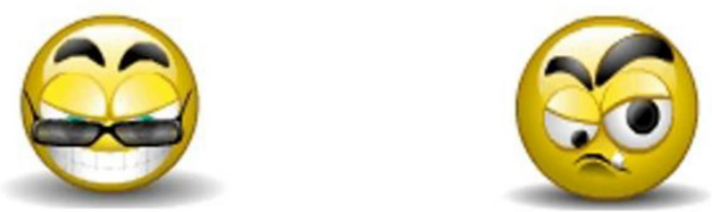

Figura 1. Procedimento de ensino utilizado no Módulo 3: trecho do livro "O caracol viajante" (tela 1), questão referente à página do livro (tela 2) e consequência diferencial para a resposta correta ou incorreta (tela 3) 


\section{MLE INTERACÃO EM PSICOLOGIA}

aplicação do instrumento DLE-3_Versão 1, o qual também foi utilizado como medida de pré-teste. Em seguida, os participantes foram alocados aleatoriamente no grupo controle e no grupo experimental e o texto "O peixão e o peixinho" foi aplicado em todos os participantes como pré-teste para avaliar a fluência de leitura.

Após os procedimentos de pré-teste, os participantes do grupo experimental foram submetidos ao Módulo 3 do programa de ensino, enquanto as crianças do grupo controle participaram somente das aulas proporcionadas pela escola em que frequentavam. Ao final da aplicação do Módulo 3, todos os participantes fizeram as atividades de pós-teste, aplicação do DLE-3_Versão 2 e leitura do texto "Um cacho de uvas". Estas etapas serão detalhadas a seguir.

\section{PROCEDIMENTOS DE SELEÇÃO DOS PARTICIPANTES}

A coordenadora da ONG indicou crianças com dificuldades de leitura com compreensão $(n=15)$ que poderiam preencher os critérios para a participação na pesquisa. Em seguida, os responsáveis pelas crianças foram contatados para apreciarem o Termo de Consentimento Livre e Esclarecido e o assinarem caso concordassem com as condições apresentadas.

Em seguida, o primeiro instrumento utilizado para seleção dos participantes foi o subteste de leitura do Teste de Desempenho Escolar (TDE). Ele foi aplicado em uma sala da ONG, em que estavam presentes somente a pesquisadora e um participante, o qual deveria ler corretamente, no mínimo, 65 palavras. Com as crianças que atingiram o critério de acerto $(n=12)$, foi realizada a aplicação do Diagnóstico da Rede de Leitura e Escrita 3_ Versão 1 (DLE-3_Versão 1) em uma sala da ONG com grupos de quatro crianças cada. Como salientado anteriormente, esse instrumento foi utilizado como critério de inclusão na pesquisa (acerto menor ou igual a 60\%) e para avaliação do repertório inicial do participante (pré-teste de leitura com compreensão). A pesquisadora enfatizou que elas deveriam ler atentamente os textos para responder às questões da melhor maneira possível e que ela não poderia auxiliá-los.

Descrição dos participantes selecionados. Participaram do estudo 11 crianças com idades entre nove e 11 anos, cursando o quarto e quinto ano do Ensino Fundamental de uma escola Municipal do interior do Paraná. Os participantes frequentavam a escola no período matutino e a ONG no período vespertino. Dos 11 participantes, dez frequentavam o reforço escolar de português. Os participantes foram divididos em grupo experimental e grupo controle, contendo seis e cinco crianças, respectivamente.

\section{Marcelle Teixeira Bertini e Camila Muchon de Melo}

\section{PROCEDIMENTOS DE PRÉ-TESTE}

Após os procedimentos de seleção dos participantes $(n=11)$ e a aplicação do DLE-3_Versão 1, a pesquisadora chamou individualmente cada criança (com desempenho inferior a $60 \%$ de acertos no DLE-3_Versão 1) para realizar a leitura do texto "O peixão e o peixinho" em voz alta, com o objetivo de avaliar a fluência de leitura. Foi solicitado ao participante que ele lesse o texto da melhor maneira que conseguisse e que sua leitura seria gravada. 0 texto continha 124 palavras e foi medido o tempo que a criança utilizava para lê-las. Desta forma, registrou-se a taxa de palavras lidas por minuto. Também foi utilizada como medida de pré-teste o resultado no DLE-3_ Versão 1. Após essas atividades com todos os participantes, iniciou-se o procedimento de ensino.

\section{PROCEDIMENTO DE ENSINO}

O Módulo 3 foi aplicado de duas a três vezes por semana, durante um período de cinco meses. Cada participante levava aproximadamente 20 minutos para ler e responder as questões solicitadas de cada livro. Na primeira sessão foi utilizado o primeiro livro do Módulo 3 para demonstrar aos participantes como ler os livros para responder às perguntas, como consultar o material lido e solicitar que o programa lesse palavras desconhecidas.

Ao iniciar as sessões, os participantes foram instruídos a ler a história sem pular palavras e se necessário, poderiam voltar ao material lido até o momento. Durante o programa de ensino, só era permitido ao participante avançar para o próximo livro após o acerto de $90 \%$ das questões apresentadas. Em caso de erro, o participante podia repetir o livro até três vezes. $\mathrm{Na}$ terceira repetição, a experimentadora sentava-se ao lado da criança e a incentivava a retornar ao conteúdo lido para responder às perguntas. Caso não atingisse os $90 \%$ de acertos, a criança prosseguia para o próximo livro.

Além das consequências programadas pelo Módulo 3, os participantes recebiam materiais escolares ao término de três sessões, independente de seus desempenhos, como cadernos, lápis, borracha, canetinhas coloridas, lápis de cor etc., os quais eram escolhidos pelas próprias crianças. Esses materiais tinham como objetivo incentivá-las a realizar as tarefas previstas no procedimento de ensino e auxiliar a população.

\section{PROCEDIMENTOS DE PÓS-TESTE}

Após cada participante do grupo experimental finalizar as atividades do currículo, foi aplicado, individualmente, o DLE3_Versão 2 para verificar o desempenho dos participantes após o procedimento realizado. Ao término dessa avaliação, foi solicitado para cada participante ler o texto "Um cacho de 


\section{MLE INTERACÃO EM PSICOLOGIA}

uvas" para análise da fluência de leitura. 0 texto continha 146 palavras e foi cronometrado o tempo que a criança utilizava para lê-lo, para registrar a taxa de palavras lidas por minuto.

A realização das atividades de pós-teste (DLE-3_Versão 2 e leitura do texto "Um cacho de uvas") com os participantes do grupo controle começou a ser realizada logo após a finalização do primeiro participante do grupo experimental nas atividades do Módulo 3. A aplicação foi feita individualmente. É importante ressaltar que os participantes do grupo controle não foram submetidos a outras atividades de leitura além das que frequentavam na escola regular, como aula e reforço.

\section{DELINEAMENTO EXPERIMENTAL E ANÁLISE DE DADOS}

Os dados obtidos foram analisados a partir de uma análise estatística, realizada no programa R Core Team (2016). Foi utilizado o teste T para amostras independentes (comparação dos resultados entre grupo controle e grupo experimental) e dependentes (comparação dos pré-teste e pós-teste intragrupo). Foi utilizado delineamento de grupo com o objetivo de a) avaliar a eficiência do Módulo 3 para ensinar leitura com compreensão, por meio dos resultados encontrados no pré-teste (DLE-3_Versão 1) e pós-teste (DLE-3_Versão 2) e da comparação do grupo experimental e do grupo controle, b) avaliar a fluência de leitura por meio da leitura dos textos "O peixão e o peixinho" (pré-teste) e "Um cacho de uvas" (pós-teste), verificando a quantidade de palavras lidas por minuto pelos participantes do grupo experimental e grupo controle.

Além disso, com o objetivo de analisar o desempenho de cada participante do grupo experimental no Módulo 3, foi registrado o número total de tentativas necessárias para que cada participante respondesse aos 15 livros do programa, assim como foi comparado o desempenho dos sujeitos com eles mesmos, nas medidas de compreensão textual (DLE-3_Versão 1 e Versão 2) e fluência de leitura ("O peixão e o peixinho" e "Um cacho de uvas") antes e após o procedimento de ensino, caracterizando-se como um delineamento de sujeito único.

\section{RESULTADOS}

Primeiramente, serão apresentados os resultados nos pré-teste e pós-teste de leitura com compreensão do grupo experimental e do grupo controle e, em seguida, serão abordados os resultados obtidos em relação à fluência de leitura para os dois grupos antes e após o procedimento de ensino, Módulo 3. Os resultados na leitura com compreensão e fluência de leitura são apresentados na Figura 2, explicitando o desempenho dos participantes. Posteriormente, são apresentados os resultados individuais dos participantes do grupo experimental, evidenciando os desempenhos das crianças
Marcelle Teixeira Bertini e Camila Muchon de Melo

durante o procedimento de ensino e as particularidades do programa. Além disso, é mostrada a quantidade de repetições por livro do programa.

Ao comparar os resultados encontrados entre os grupos, foram evidenciados resultados médios estatisticamente semelhantes nos pré-teste de compreensão de leitura, 49,29\% de acertos do grupo experimental e $41,66 \%$ do grupo controle ( $p$-value $=0.3703)$, o que indica que os grupos apresentavam desempenhos equivalentes antes de serem expostos ao programa. Após o procedimento de ensino, observou-se melhora significativa de desempenho em leitura com compreensão para o grupo experimental (de $49,29 \%$ para $68,75 \%$ ) se comparado com o grupo controle $(41,66 \%$ para $51,66 \%)$. Sobre o pré-teste de fluência de leitura (texto "O peixão e o peixinho"), os grupos obtiveram médias aproximadas de palavras lidas por minuto (p.p.m.), 70 p.p.m. no grupo experimental e 61 p.p.m. no grupo controle ( $p$-value $=0.4223$ ), indicando também desempenhos equivalentes entre os grupos, antes da exposição ao programa. Após o procedimento de ensino, o grupo experimental leu mais palavras por minuto (90 p.p.m.) se comparado ao grupo controle (73 p.p.m), mas essa diferença não foi significativa.

$\mathrm{Na}$ Figura 2 são apresentados os resultados obtidos pelos participantes no pré-teste e pós-teste (DLE-3) dos dois grupos no que se refere à compreensão e à fluência de leitura. Observou-se um aumento na porcentagem de acertos nas avaliações de compreensão de leitura, assim como na fluência, para todos os participantes do grupo experimental.

Ao comparar o grupo com o seu próprio desempenho, demonstrou-se diferença significativa entre os resultados médios do pré-teste e pós-teste na medida de compreensão de leitura $(p$-value $=0.004549)$ e de fluência de leitura ( $p$-value $=0.002958$ ). No grupo controle não foi observada diferença significativa entre os resultados da compreensão de leitura $(p$-value $=0.2546)$ e da fluência de leitura $(p$-value $=0.09929)$.

Na Tabela 1 são apresentados os desempenhos dos participantes do grupo experimental de acordo com as respostas realizadas no Módulo 3 . A tabela contém o número total de "realizações" que cada participante utilizou para responder aos 15 livros (cada livro podia ser lido três vezes caso o participante acertasse menos de $90 \%$ das questões); informa sobre a utilização de recursos disponibilizados pelo programa, como o número total de palavras consultadas (pedir para o programa ler palavras) e pedidos de ajuda (retornar à página anterior da história para ler novamente e responder às perguntas) durante toda a realização do programa (o quanto fosse necessário). Além disso, apresenta a fluência antes e após a análise da leitura dos textos "O peixão e o peixinho" e "Um cacho de uvas", assim como, a porcentagem de acertos no pré-teste e pós-teste de compreensão de leitura. 

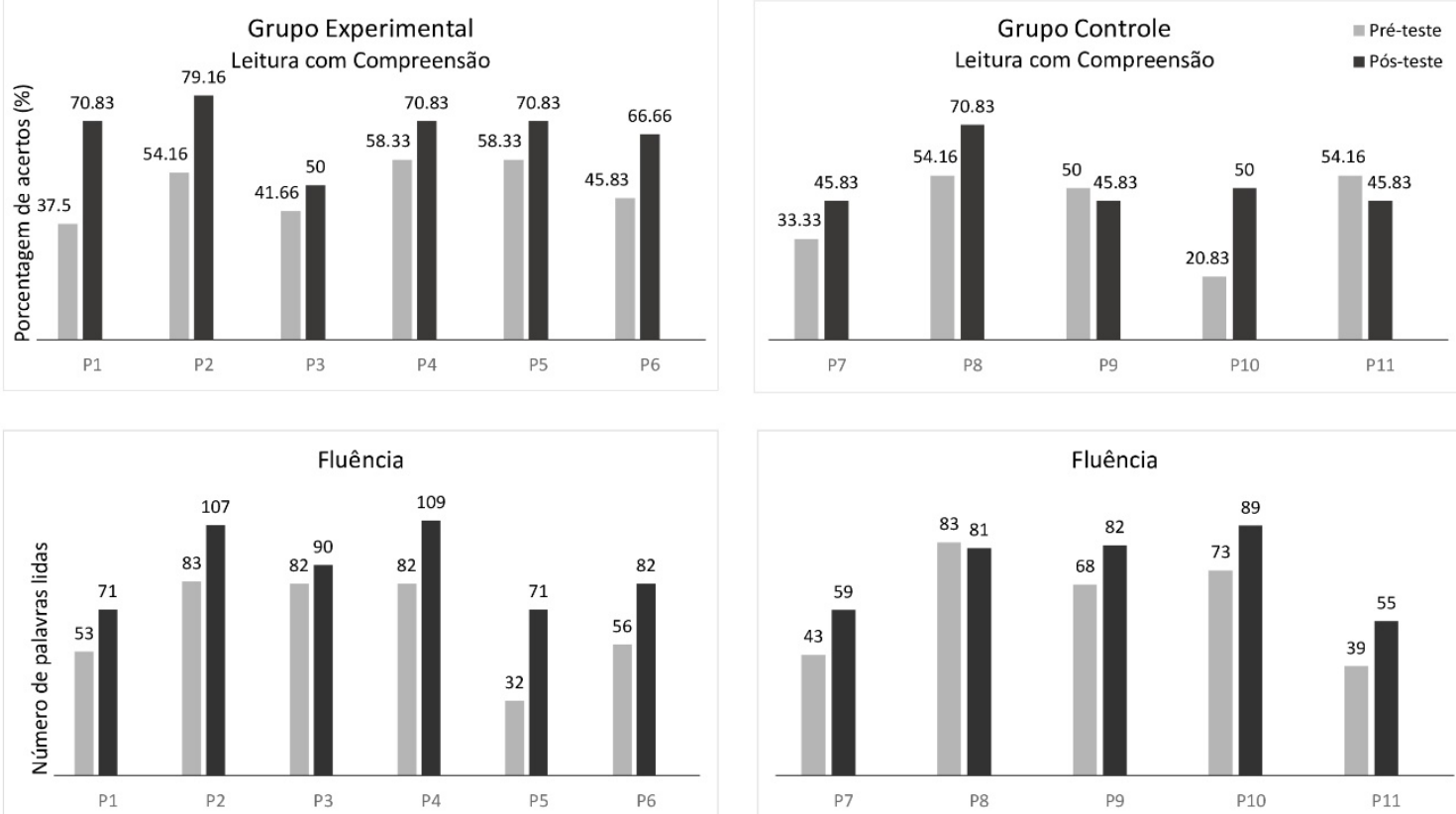

Figura 2. Desempenho individual dos participantes dos grupos experimental e controle para a compreensão de leitura (em porcentagem de acertos no programa) e para a fluência de leitura (número de palavras lidas por minuto).

Tabela 1. Desempenho individual dos participantes do grupo experimental no decorrer do Módulo 3

\begin{tabular}{cccccc}
\hline Participantes & $\begin{array}{c}\text { Total de } \\
\text { realizações para } \\
\text { responder os } \\
\text { 15 livros }\end{array}$ & $\begin{array}{c}\text { No de } \\
\text { palavras } \\
\text { consultadas }\end{array}$ & $\begin{array}{c}\text { Quantidade de } \\
\text { pedidos de } \\
\text { ajuda }\end{array}$ & $\begin{array}{c}\text { Pré e pós-teste } \\
\text { de Fluência em } \\
\text { leitura }\end{array}$ & $\begin{array}{c}\text { Pré e pós-teste } \\
\text { de Leitura com } \\
\text { compreensão }\end{array}$ \\
\hline P1 & 29 & 427 & 57 & $53-71$ & $37,50 \%-70,83 \%$ \\
P2 & 21 & 571 & 34 & $83-107$ & $54,16 \%-79,16 \%$ \\
P3 & 28 & 117 & 79 & $82-101$ & $41,66 \%-50 \%$ \\
P4 & 30 & 1335 & 67 & $82-109$ & $58,33 \%-70,83 \%$ \\
P5 & 28 & 9 & 77 & $62-71$ & $58,33-70,83 \%$ \\
P6 & 31 & 460 & 139 & $56-82$ & $45,83 \%-6,66 \%$ \\
\hline
\end{tabular}

Nota. $\mathrm{N}^{\circ}=$ número.

Nota-se que P1 foi o participante que obteve maior aumento na porcentagem de acertos em compreensão de leitura (33,33\%), chegando a $70,83 \%$ de acertos. Além disso, foi o terceiro participante com mais "realizações" (29) para responder aos 15 livros do programa, ou seja, usou em média duas repetições por livro. P3 foi a participante com menor aumento de porcentagem de acertos em compreensão de leitura 8,34 \%, com $50 \%$ de acertos, sendo a terceira participante em número de realizações por livros (28), ou seja, usou em média 1,8 "realizações" por livro para cumprir as atividades do programa. P4 foi a participante que teve o maior aumento na fluência, leu 27 palavras a mais no pós-teste, consultou mais palavras se comparada com os outros participantes, atingindo um total de 1335 palavras, e foi uma das que apresentou mais realizações para responder aos 15 livros do programa de ensino, em média duas por livro; essa participante teve um aumento de $12,5 \%$, acertando $70,83 \%$ de questões no pós-teste de compreensão de leitura (DLE-3_Versão 2). 
Na Figura 3 é possível observar a quantidade média de realizações feitas pelos participantes em cada livro do programa, ou seja, quando o participante não atingia $90 \%$ de acertos ele tinha que se expor novamente àquele determinado livro. Nota-se que houve maior repetição dos livros no início da unidade 1 (livros de 1 a 5) e a partir do final da segunda unidade até a terceira (do livro 10 em diante). Observou-se que a alteração da ordem dos livros (8 e 9; 13 e 14) não afetou a diminuição dos erros e repetições da unidade 3 .

\section{DISCUSSÃO}

Esta pesquisa teve como objetivo avaliar a eficiência de um programa de ensino informatizado (ALLEP), especificamente do Módulo 3 do programa, para promover comportamentos de leitura com compreensão e verificar se houve alteração no número de palavras lidas por minuto, variável fundamental para fluência de leitura, a partir da comparação de resultados encontrados no pré-teste e pós-teste realizados pelo grupo experimental e grupo controle. Além disso, analisou-se o desempenho dos participantes individualmente, comparando o desenvolvimento do seu próprio repertório, ao longo de todo procedimento de ensino.

Em relação à compreensão de leitura, é possível afirmar que o programa auxiliou todos os participantes $(n=6)$ do grupo experimental a aumentarem a porcentagem média de acertos no pós-teste de leitura com compreensão, se comparado com o pré-teste, sugerindo melhora nos desempenhos em leitura com compreensão, enquanto que para o grupo controle, apenas três participantes obtiveram resultados superiores aos pré-teste. As análises estatísticas demonstraram que o aumento de acertos foi significativo para o grupo experimental, quando comparado com o seu próprio desempenho e quando comparado com o grupo controle. Para o grupo controle, a porcentagem de acertos no pós-teste em relação ao pré-teste não foi signifıcativa.

Apesar de todos os participantes do grupo experimental terem aumentado a porcentagem de acertos no pós-teste, dois participantes obtiveram desempenhos finais baixos para compreensão textual: P3 atingiu apenas $50 \%$ de respostas corretas e P6 acertou apenas $66,6 \%$ das questões. Esses resultados indicam a necessidade da inserção de estratégias que poderiam dar suporte aos aprendizes com desempenhos como esses, próximos ao nível considerado insuficiente para leitura com compreensão ( $60 \%$ de acertos). Uma sugestão seria a inclusão de passos adicionais no programa para aumentar gradativamente a complexidade dos livros e questões, principalmente no Nível de Ensino 3 do Módulo 3. Observou-se um aumento no número de realizações por livros nesse nível, decorrente de mais erros nas respostas emitidas pelos participantes. Outra sugestão seria o programa adicionar instruções mais evidentes sobre a possibilidade de retorno ao material lido para responder às perguntas referentes aos textos.

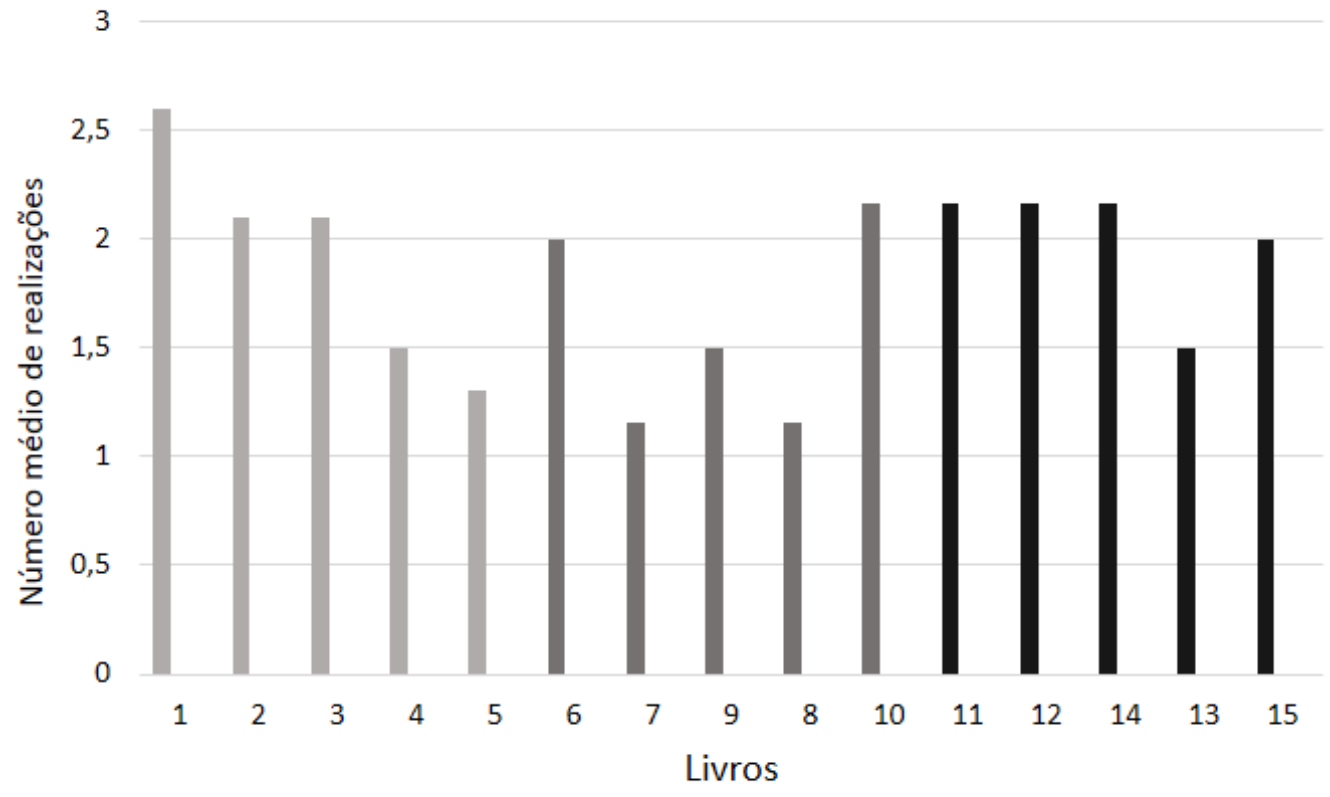

- Nivel de Ensino 1 a Nível de Ensino 2 a Nível de Ensino 3

Figura 3. Número médio de realizações feitas de cada livro do Módulo 3, pelos participantes. 


\section{H. INTERACÃO EM KT PSICOLOGIA}

Em pesquisa realizada por Hanna et al. (2015a), com alunos do terceiro e quinto ano de duas escolas públicas de Brasília, foi demonstrado que os resultados nos DLEs foram consistentes com os resultados na Prova Brasil, que avalia a compreensão de leitura em alunos da educação básica em âmbito nacional. As autoras também demonstraram que a maioria das crianças obteve desempenho inferior aos $60 \%$ de acertos, o que pode significar baixo desempenho em habilidades esperadas para aquelas faixas etárias se comparadas com as habilidades esperadas pela Prova Brasil. Portanto, os resultados acima de $60 \%$ no pós-teste do grupo experimental do presente estudo também podem ser um indicativo de que o Módulo 3 foi eficiente para ensinar o repertório de leitura com compreensão para a maioria dos participantes submetidos ao procedimento, visto que no grupo controle somente um participante atingiu essa média.

Hanna et al. (2015b), em publicação realizada em anais de congresso, demonstraram que a aplicação desse módulo ensinou comportamentos de leitura com compreensão para crianças do quarto ano do Ensino Fundamental. Além disso, as autoras consideraram a ordem de apresentação dos livros e demonstraram que os participantes apresentaram maior número de erros e repetições no livro 8 , se comparado ao livro 7 , fato que também aconteceu no livro 13 em relação ao livro 12. A partir dos resultados encontrados na pesquisa de Hanna et al. (2015b) foi invertida a ordem de aplicação entre os livros 8 e 9, e 14 e 13, para verificar uma possível diminuição do número de erros dos participantes, devido à hipótese de que a ordem de complexidade desses livros poderia estar disposta do mais complexo para o mais simples. Entretanto, os resultados obtidos no presente estudo demonstraram que a inversão na ordem desses livros produziu resultados semelhantes aos do estudo de Hanna et al. (2015b), ou seja, a alteração dessa ordem não facilitou à aprendizagem.

Ao comparar a quantidade de erros e realizações dos livros com o pressuposto de que os livros deveriam ser apresentados dos: a) mais simples para o mais complexo e b) em pequenos passos (Skinner, 1968/1972), foi possível observar que a maioria dos participantes repetiu mais vezes os livros no início do Módulo 3, quando estavam aprendendo a realizar a tarefa proposta, e quando avançaram para a terceira unidade (livros 11 ao 15). Esses resultados podem indicar a necessidade de mais decomposições das etapas do procedimento de ensino, com o objetivo de diminuir a quantidade de erros (Skinner, 1968/1972), uma vez que observou-se um aumento no número de repetições do final do segundo nível para o terceiro nível.

Vale ressaltar que o presente estudo é um dos primeiros no que diz respeito ao uso do Módulo $3 \mathrm{com}$ a finalidade de avaliar a sua eficácia para a compreensão de leitura, visto que não foram encontradas muitas referências sobre esse módulo.
Marcelle Teixeira Bertini e Camila Muchon de Melo

Além disso, dos estudos citados, nenhum avaliou o efeito do módulo sobre a fluência de leitura. A fluência tem sido considerada um repertório importante para realizar leitura com compreensão (Navas et al., 2009) e não foi analisada nos outros estudos, sendo assim, este estudo apresenta avanços no conhecimento sobre a eficácia do Módulo 3.

Sobre a fluência de leitura, observou-se que a maioria dos participantes, dos grupos controle e experimental, aumentou a quantidade de palavras lidas por minuto. Apesar das análises demonstrarem que não houve diferença significativa na taxa de leitura quando comparados os grupos, somente o grupo experimental apresentou diferença significativa nessa medida quando comparado com o seu próprio desempenho. Como dito anteriormente, a literatura aponta a fluência de leitura como requisito importante para compreensão de textos, sendo a taxa de leitura fator crucial na determinação da mesma, visto que indivíduos que apresentam maior automaticidade para decodificar geralmente se atentam para outros aspectos do texto (Navas et al., 2009).

Análises dos desempenhos individuais dos participantes do grupo experimental não permitiram conclusões claras sobre a relação entre as medidas de leitura com compreensão e da fluência. Por exemplo, o participante P1 que obteve maior aumento no número de acertos $(33,33 \%)$, chegando a $70,83 \%$ de respostas corretas no pós-teste de leitura com compreensão, não foi o participante que mais aumentou a quantidade de palavras lidas por minuto. Por outro lado, a participante que leu mais palavras por minuto no grupo experimental (P4), apesar de atingir os mesmos $70,83 \%$ de acertos no pós-teste que $\mathrm{P} 1$, foi uma das que menos aumentou o número de questões corretas (12,5\%), entretanto, isso pode ser devido ao fato dessa participante ter iniciado no pré-teste com um valor relativamente alto de acertos. No grupo controle, o participante P8, que obteve mais acertos no pós-teste de leitura com compreensão $(70,83 \%)$, foi o que teve uma pequena diminuição no número de palavras lidas por minuto (83 p.p.m - pré-teste/ 81 p.p.m - pós-teste). Sendo assim, os resultados do presente estudo não permitem corroborar a hipótese de que há uma relação direta entre fluência e a compreensão de leitura. Possivelmente existe um nível ótimo de velocidade da leitura que seja compatível com a compreensão do material lido, o que não implica dizer que quando a velocidade aumenta, também aumenta a compreensão, mas sim que existe um limiar confortável de número de palavras lidas por minuto de modo a não prejudicar a compreensão, visto que para compreender o texto lido, o leitor também necessita de outros comportamentos além de discriminar corretamente letras e sons, como estabelecer relações entre palavras e estímulos discriminativos do ambiente e identificar o contexto em que essas palavras são emitidas. 


\section{WINTERAÇO EM PSICOLOGIA}

Sobre a interação das crianças com o procedimento de ensino, notou-se que elas utilizavam em menor quantidade o recurso de "retornar ao material lido". Foram notados comportamentos "impulsivos" para responder às questões, gerando erros e os subprodutos deletérios do erro para as novas aprendizagens (Melo, Carmo, \& Hanna, 2014). Laying et al. (2011) citam a importância de retornar ao texto para procurar palavras-chave que remetam ao que uma questão de interpretação textual solicita. Neste caso, estratégias educacionais adicionais que incentivem o participante a utilizar mais esse recurso poderiam ser acrescidas ao Módulo 3.

A partir dos resultados conclui-se que o Módulo 3 foi eficiente para desenvolver comportamentos de leitura com compreensão, quando comparados os grupos experimental e controle, para a maioria dos participantes. Sobre a fluência de leitura, especificamente a medida da taxa de palavras lidas por minuto, foi possível observar que ao analisar os desempenhos dos grupos com eles mesmos, notou-se que a média de palavras lidas por minuto no pós-teste feito pelo grupo experimental teve resultado significativamente maior se comparado com o pré-teste. Desta maneira, é possível sugerir que o Módulo 3 também auxiliou os participantes desse grupo a aumentarem a fluência, mesmo que este não tenha sido o objetivo do programa de ensino. Por outro lado, não foi verificada uma relação de dependência entre o maior número de palavras lidas por minuto (medida da fluência) e o aumento na medida de compreensão textual. Em estudos posteriores sugere-se um aumento na quantidade de participantes dos grupos controle e experimental para melhor avaliação dos resultados encontrados após aplicação do Módulo 3, visto que isso permitirá resultados mais abrangentes à população, servindo como "medida" para a qualidade do programa utilizado.

\section{AGRADECIMENTOS}

As autoras agradecem a professora Dra. Camila Domeniconi da Universidade Federal de São Carlos (INCT/ECCE), por todas as contribuições imprescindíveis para a elaboração desta pesquisa, das ideias iniciais até a redação final do manuscrito. Agradecemos também ao Instituto Nacional de Ciência e Tecnologia sobre Comportamento, Cognição e Ensino (INCT/ECCE), especialmente às professoras Dra. Deisy das Graças de Souza e Dra. Elenice Hanna, por ter cedido o Programa de Ensino utilizado neste estudo.

\section{CONTRIBUIÇÃO DE CADA AUTOR}

Certificamos que todos os autores participaram suficientemente do trabalho para tornar pública sua responsabilidade pelo conteúdo. A contribuição de cada autor pode ser atribuída como se segue:
Marcelle Teixeira Bertini e Camila Muchon de Melo

M.T.B e C.M.de M. contribuíram para a conceitualização, metodologia e redação do artigo; M.T.B foi responsável pela investigação e C. M. de M. foi responsável pela supervisão do manuscrito.

\section{DECLARAÇÃO DE CONFLITOS DE INTERESSE}

Os autores declaram que não há conflitos de interesse no manuscrito submetido.

\section{REFERÊNCIAS}

Alliende, F.; Condemarin, M.; Chadwick, M.; Milicié, N. (1994). Compreensão da Leitura 1: Fichas para o desenvolvimento da compreensão de leitura. Editorial Psy II.

Aran, M. A. de S. (2016). Efeito do ensino de sinônimos sobre a compreensão de textos. Dissertação de Mestrado. http:// www.ppgpsi.ufscar.br/pdf/Dissmasa_222222.pdf.

Benitez, P. B.; Domeniconi, C. (2012). Verbalizações de familiares durante aprendizagem de leitura e escrita por deficientes intelectuais. Estudos de Psicologia (Campinas), 29 (4), 553-562. https://dx.doi.org/10.1590/S0103166X2012000400010.

Cardoso-Martins, C.; Navas, A. L. (2016). O papel da fluência de leitura de palavras no desenvolvimento da compreensão da leitura: Um estudo longitudinal. Educar em Revista, (62), 17-32. https://doi.org/10.1590/0104-4060.48307.

Carvalho, B. S. da S. (2013). Programações de ensino para refinamento de habilidades de leitura e escrita de um aluno com Transtorno de Asperger. Dissertação de Mestrado. https:// repositorio.ufscar.br/bitstream/handle/ufscar/3128/5017. pdf?sequence $=1$

De Rose, J. C. (1993). Classes de estímulo: Implicações para uma análise comportamental da cognição. Psicologia: Teoria e Pesquisa, 9 (2), 283-303.

De Rose, J. C.; De Souza, D. G.; Rossito, A. L.; De Rose, T. M. S. (1989). Aquisição de leitura após história de fracasso escolar: Equivalência de estímulos e generalização. Psicologia: Teoria e Pesquisa, 5 (3), 325-346.

De Rose, J. C.; De Souza, D. G.; Hanna, E. S. (1996). Teaching reading and spelling: Exclusion and stimulus equivalence. Journal of applied behavior analysis, 29 (4), 451-469. https://doi.org/10.1901/jaba.1996.29-451.

De Souza, D. das G.; de Rose, J. C. (2006). Desenvolvendo programas individualizados para o ensino de leitura. Acta Comportamentalia, 14 (1), 77-98. http://revistas.unam. $\mathrm{mx} /$ index.php/acom/article/viewFile/14532/13859.

De Souza, D. das G.; de Rose, J. C.; Domeniconi, C. (2009) Applying relational operants to reading and spelling. In $\mathrm{R}$. A Rehfeldt, Y. Barnes-Holmes. Derived relational responding: Applications for learners with autism and other developmental disabilities. New Harbinger Publications, 171-207. 


\section{H MTERAC̄OOEM ET PSICOLOGIA}

De Souza, D. das G.; de Rose, J. C.; Faleiros, T. C.; Bortoloti, R., Hanna, E. S.; MCllvane, W. J. (2009). Teaching generative reading via recombination of minimal textual units: A legacy of verbal behavior to children in Brazil. Revista Internacional de Psicologia y Terapia Psicológica, 9, 19-44.

De Souza, D. das G.; de Rose, J. C.; Fonseca, M. L.; Hanna, E. S. (1999). Stimulus control research and minimal units for reading. Experimental Analysis of Human Behavior Bulletin, 17, 20-23.

De Souza, D. das G.; de Rose, J. C.; Hanna, E. S.; Calcagno, S.; Galvão, O. F. (2004). Análise comportamental da aprendizagem da leitura e escrita e a construção de um currículo suplementar. In M. M. Hübner, M. Marinotti (Eds.), Análise do Comportamento para educação - contribuições recentes (p.177-203). Esetec.

De Souza, D. das G.; Hanna, E. S.; de Albuquerque, A. R.; Hübner, M. M. C. (2014). Processos recombinativos: Algumas variáveis críticas para o desenvolvimento de leitura. In J. C. de Rose, M. S. C. A. Gil, D. das G. de Souza (Eds.), Comportamento simbólico: Bases conceituais e empíricas (p.421-462). Cultura Acadêmica.

Domeniconi, C.; Hanna, E. S.; de Rose, J.C.C; de Souza, D.G. (submetido). Programa individualizado de compreensão de leitura melhora resultados na Prova Brasil. Estudos em Avaliação Educacional.

Domeniconi, C.; Silveira, C.; Hanna, E. S. (2013). Diagnóstico de Leitura e Escrita - Compreensão de Textos. Instrumento de avaliação não registrado.

Ehri, L. C. (2005). Learning and reading words: Theory, findings, and issues. Scientific Studies of Reading, 9 (2), 167-188. https://miblsi.org/sites/default/files/Documents/Presentations/AnitaArcherWorkshops/January2014/LearningtoReadWords.pdf.

Hanna, E. S.; de Souza, D. G.; de Rose, J. C.; Fonseca, M. (2004). Effects of delayed constructed-response identity matching on spelling of dictated words. Journal of Applied Behavior Analysis, 37(2), 223-227. https://doi. org/10.1901/jaba.2004.37-223.

Hanna, E. S.; Santos, A. P.; Saar, B.; Scandiuzzi, B.; Diaz, F.; Domeniconi, C. (2015a). Mapeamento de repertório básico de leitura e escrita e sua utilidade para intervenções com alunos de escolas públicas de Brasília. Trabalho apresentado na $67^{\mathrm{a}}$ Reunião Anual da Sociedade Brasileira para o Progresso da Ciência. http://www.sbpcnet.org.br/livro/67ra/ resumos/resumos/4936_137b00326f2fec4964c62ac4fec9279da.pdf.

Hanna E. S.; Vieira, C. O.; Moraes, L. U. de; Silva, L. R. de S.; Rangel, P. C. N.; Domeniconi, C. (2015b). Desenvolvimento de compreensão de histórias infantis a partir de leitura interativa via computador. Trabalho apresentado na $67^{\mathrm{a}}$ Reunião Anual da Sociedade Brasileira para o Progresso da Ciência. http://www.sbpcnet.org.br/livro/67ra/resumos/ resumos/4936_237b00326f2fec4964c62ac4fec9279da.pdf
Marcelle Teixeira Bertini e Camila Muchon de Melo

Holland, J. G.; Skinner, B. F. (1961). The analysis of behavior: A program for self-instruction. McGraw-Hill.

Horne, J. K. (2017). Reading comprehension: A computerized intervention with primary-age poor readers. Dyslexia, 23(2), 118-140. https://doi.org/10.1002/dys.1552

Indicador de alfabetismo functional. (2018). http://acaoeducativa.org.br/wp-content/uploads/2018/08/Inaf2018_Relat\%C3\%B3rio-Resultados-Preliminares_v08Ago2018.pdf

Keller F. S. (1968). "Good-bye, teacher...". Journal of applied behavior analysis, 1(1), 79-89. https://doi.org/10.1901/ jaba.1968.1-79

Layng, T. V. J.; Sota, M.; Leon, M. (2011). Thinking through text comprehension I: Foundation and guiding relations. The Behavior Analyst Today, 12 (1), 3-11. https://doi. org/10.1037/h0100706

Melo, R. M. de; Carmo, J. dos S.; Hanna, E. S. (2014). Ensino sem erro e aprendizagem de discriminação. Temas em Psicologia, 22 (1), 207-222. https://doi.org/10.9788/ TP2014.1-16

Navas, A. L. G. P.; Pinto, J. C. B. R.; Dellisa, P. R. R. (2009). Avanços no conhecimento do processamento da fluência em leitura: Da palavra ao texto. Revista da Sociedade Brasileira de Fonoaudiologia, 14 (3), 553-559. https://doi. org/10.1590/S1516-80342009000400021

R Core Team (2016). R: A language and environment for statistical computing. R Foundation for Statistical Computing. https://www.R-project.org/

Reis, T. S.; de Souza, D. das G.; de Rose, J. C. (2009). Avaliação de um programa para o ensino de leitura e escrita. Estudos em Avaliação Educacional, 20 (44), 425-449.

Rocca, J. Z. (2012). O conceito de símbolo em Sidman e Skinner: Uma análise epistemológica (Tese de Doutorado). https://www.researchgate.net/profile/Julia_Rocca/public ation/225071233_0_conceito_de_simbolo_em_Skinner_e_ Sidman_-_uma_analise_epistemologica/links/5404a$5 f 60$ cf2c48563b0eff1/0-conceito-de-simbolo-em-Skinner-e-Sidman-uma-analise-epistemologica.pdf.

Sidman, M. (1994). Equivalence relations and behavior. A research story. Authors Cooperative.

Skinner, B. F. (1957). Verbal Behavior. Prentice Hall.

Skinner, B. F. (1972). The Technology of Teaching. AppletonCentury-Crofts. Trabalho original publicado em 1968.

Stein, L. M. (1994). TDE - teste de desempenho escolar: Manual para aplicação e interpretação. Casa do Psicólogo.

Data de submissão: 04 de fevereiro de 2019 Primeira decisão editorial: 07 de abril de 2019 Aprovação: 10 de julho de 2020 